\title{
Large-Scale Exploitation of Bimodal Reaction Sequences Including Degradation: Comparison of Jet Loop and Trickle Bed Reactors
}

\author{
Jeroen Poissonnier, Joris W. Thybaut, ${ }^{*}$ a and Guy B. Marin ${ }^{\circledR}$ \\ Laboratory for Chemical Technology, Ghent University, Technologiepark 914, B-9052 Gent, Belgium
}

\begin{abstract}
Product yield optimization in bimodal reaction sequences including degradation has been performed considering three-phase reactors such as the jet loop and trickle bed reactors. The considered reaction network comprises two consecutive homogeneous reaction steps toward intermediates which are converted to the corresponding final products by heterogeneously catalyzed reactions, while the reactant and these intermediates are susceptible to irreversible degradation. In the jet loop reactor, the so-called "homogeneous product" is the main product; hence, the remaining challenge is the reduction of degradation. For the trickle bed reactor, gas-liquid mass phase transfer plays a very pronounced role in its ultimate performance. Higher gas flow rates may be employed in the trickle bed reactor to overcome potential mass-transfer limitations and selectively form the "heterogeneous product". Lower gas flow rates result in a less effective gas dissolution, and product selectivities change toward the homogeneous product, rendering avoiding degradation difficult.
\end{abstract}

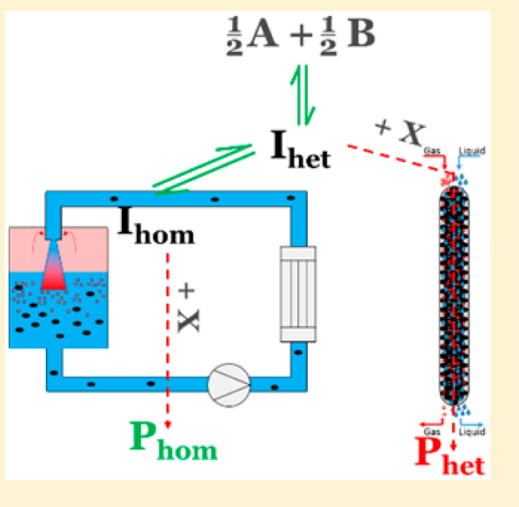

\section{INTRODUCTION}

Several chemical processes comprise a combination of homogeneous bulk-phase reactions and heterogeneously catalyzed ones, the reductive amination of aldehydes, ketones, and alcohols being a notorious example. ${ }^{1-3}$ Relevant reaction schemes involve bulk-phase amination steps along with heterogeneously catalyzed reduction steps. Proper optimization of this interplay between bulk phase and heterogeneously catalyzed reactions allows the selective formation of primary, secondary, or tertiary amines, as required. Industrially, the reductive amination of alcohols is performed in fixed bed gasphase or three-phase trickle bed reactor systems, whereas stirred tank reactors are used for the reductive amination of aldehydes or ketones. ${ }^{4}$ The latter is imposed by safety constraints as the heat of reaction is significantly higher for the amination of carbonyl feedstocks compared to that of alcohols. Oxidative coupling of methane is another well-known reaction requiring heterogeneously catalyzed and gas-phase reactions. Methane activation proceeds heterogeneously on the catalyst surface, the resulting radicals being coupled homogeneously in the gas phase of fixed bed reactors. ${ }^{5,6}$ Three-phase ozonation of oxalic acid in wastewater treatment is performed in slurry reactors, and operating conditions are chosen such that noncatalytic ozone decomposition is limited. ${ }^{7}$

Compared to stirred tank reactors, loop reactors are more and more appreciated because they are safer and mass transfer is enhanced at a lower power cost, as has been demonstrated for ethoxylation and propoxylation processes. ${ }^{8}$ Especially for ethoxylation, a loop reactor is preferred as the extent of the highly exothermic gas-phase decomposition of ethylene oxide can be minimized as a consequence of the better gas-liquid mass transfer. Also, the ignition of the gas mixtures is prevented as no mechanical stirrer is present in this reactor. ${ }^{8}$ Furthermore, loop reactors are simple in design and are most suitable for fast reactions where gas-liquid mass transfer can be limiting, such as in phosgenations, aminations, and hydrogenations. ${ }^{9,10}$ Mixing is also very fast, and apart from high mass-transfer efficiencies, high heat-transfer efficiencies are obtained via the heat exchanger in the reactor's loop. Loop reactors are also preferred for the easy scale-up ability, as was shown for the reductive alkylation of amines. ${ }^{11}$ However, given the low catalyst content, loop reactors are deemed to be suboptimal for solely heterogeneously catalyzed reactions and hence are more appropriate for multiphase applications involving also homogeneous reactions. ${ }^{12}$

Heterogeneously catalyzed reactions not involving any bulkphase reactions are typically performed in three-phase trickle bed reactors, such as for aromatics hydrogenation. ${ }^{13}$ In this case, mass transfer from the gas to the liquid phase was identified as rate-limiting in the initial stage of the reaction. Similar conclusions were obtained for hydrotreatment reactions in trickle bed reactors, the limitations being even more pronounced on the pilot plant scale than on the industrial scale as higher liquid velocities are reached on the latter scale. ${ }^{14}$

Trickle bed reactor models have also been presented for reactions consuming liquids with a non-negligible vapor pressure, such as the hydrogenation of cyclohexene to cyclohexane. It was shown that reaction rates are significantly enhanced at operating conditions leading to only a partial catalyst wetting. ${ }^{15}$

In our previous work we discussed the effect of the catalyst amount on the product spectrum in bimodal reaction sequences. ${ }^{16}$ In the present work, we expand the framework

Received: August 3, 2017

Revised: October 26, 2017

Accepted: October 31, 2017

Published: October 31, 2017 
by adding gaseous reactants, also accounting for the possible limitations related to the gas-liquid mass transfer, and by including degradation reactions. Reactor simulations are performed aiming at the selective production of heterogeneous or homogeneous reaction products while avoiding degradation. The transfer of a light gas and its dissolution in the liquid phase plays a critical role. The considered reactor types range from slurry to fixed bed reactors; the jet loop reactor is representative for the former reactor type and the trickle bed for the latter reactor type.

\section{PROCEDURES}

Reaction Network and Kinetics. The considered reaction network, see Figure 1, is an extended version of the previously

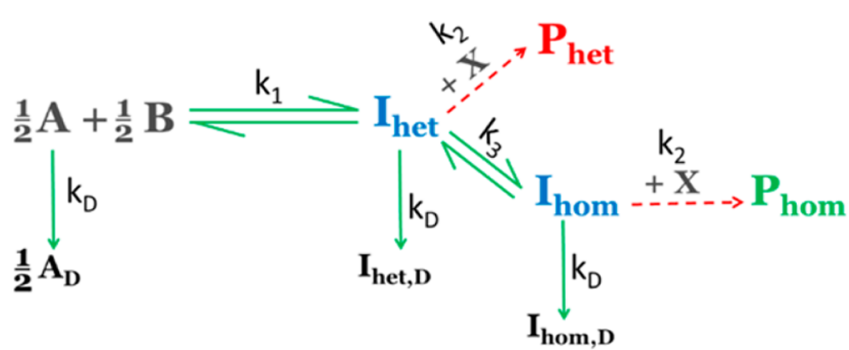

Figure 1. Reaction network used for the optimization study. Homogeneous bulk-phase reactions are represented by green solid lines, while heterogeneously catalyzed reactions are represented by red dotted lines. The corresponding rate and equilibrium coefficients are presented in Table 1 .

employed one. It involves the formation of a heterogeneous product " $\mathrm{P}_{\text {het }}$ " and a homogeneous product " $\mathrm{P}_{\text {hom }}$ " and is based on glucose reductive aminolysis. ${ }^{17}$

In a first step, a nonvolatile reactant " $A$ " mixed with a solvent reacts with a reactant " $B$ ", having a non-negligible vapor pressure, in the liquid phase with the formation of two identical heterogeneous intermediates, denoted as " $\mathrm{I}_{\text {het }}$ ". This heterogeneous intermediate can be converted to the homogeneous intermediate " $\mathrm{I}_{\text {hom }}$ " through a consecutive liquid-phase reaction. Both intermediates can be converted to the respective products via a heterogeneously catalyzed reaction with a dissolved gas " $X$ ". The components $A, I_{\text {het, }}$ and $I_{\text {hom }}$ are furthermore susceptible to unimolecular irreversible degradation to the components represented with the subscript " $D$ " in Figure 1.

The first step is based on the reaction of a carbohydrate molecule containing four carbon atoms, which is dissolved in water, with dimethylamine toward two molecules consisting of two carbon atoms in the carbohydrate backbone. A condensation of dimethylamine with the carbohydrate and a retro-aldol cleavage reaction step are thus lumped together in this step. The consecutive homogeneous reaction stems from the keto-enol tautomerism, while the heterogeneously catalyzed reactions are hydrogenation reactions. The degradation reactions comprise all possible steps involved in carbohydrate degradation.

The rate coefficients used for the reaction network given in Figure 1 are reported in Table 1, along with the values of the adsorption equilibrium coefficients and thermodynamic equilibrium coefficients. These values originate from previous work but have been extended and tuned to better illustrate the effects of the various phenomena that may occur with the presently considered reaction network. ${ }^{16,17}$ Among others, this tuning involves capturing the effects of homogeneous catalysis, as they
Table 1. Rate Coefficients, Thermodynamic Equilibrium Coefficients, and Adsorption Equilibrium Coefficients for the Reaction Network Shown in Figure 1

\begin{tabular}{|c|c|c|c|}
\hline \multicolumn{2}{|l|}{ Rate coefficients } & \multicolumn{2}{|c|}{ Thermodynamic equilibrium coefficients [-] } \\
\hline $\mathrm{k}_{1}\left[\mathrm{~m}_{\mathrm{L}}^{3} \mathrm{~mol}^{-1} \mathrm{~s}^{-1}\right]$ & $5 \cdot 10^{-6}$ & $\mathrm{~K}_{1}$ & $1 \cdot 10^{1}$ \\
\hline $\mathrm{k}_{2}\left[\mathrm{~mol} \mathrm{~kg}_{\mathrm{cat}}{ }^{-1} \mathrm{~s}^{-1}\right]$ & $5 \cdot 10^{-1}$ & $\mathrm{~K}_{3}$ & $1 \cdot 10^{2}$ \\
\hline $\mathrm{k}_{3}\left[\mathrm{~s}^{-1}\right]$ & $5 \cdot 10^{-2}$ & Adsorption equilil & ents $\left[\mathrm{m}_{\mathrm{L}}^{3} \mathrm{~mol}^{-1}\right]$ \\
\hline $\mathrm{k}_{\mathrm{D}}\left[\mathrm{s}^{-1}\right]$ & $1 \cdot 10^{-4}$ & $\begin{array}{l}\mathrm{K}_{\mathrm{ads}, \mathrm{I} \text { het }}=\mathrm{K}_{\mathrm{ads}, \mathrm{I}_{\mathrm{hom}}} \\
\mathrm{K}_{\mathrm{ads}, \mathrm{X}}\end{array}$ & $\begin{array}{l}1 \cdot 10^{-1} \\
1\end{array}$ \\
\hline
\end{tabular}

occur in the reductive aminolysis, in the considered rate coefficients, i.e., in $k_{1}$ and $k_{3}$.

Equations 1-7 illustrate how the reaction rates are calculated for the reaction network shown in Figure 1. Mathematically, it is most straightforward to express the rates of both the heterogeneously catalyzed and homogeneous bulk-phase reactions as a function of the reactor volume. In this way these expressions can be directly used in the corresponding reactor equations.

$$
\begin{aligned}
& r_{1}=k_{1}\left(C_{\mathrm{A}} C_{\mathrm{B}}-\frac{C_{\mathrm{I}_{\text {het }}}^{2}}{K_{1}}\right) \varepsilon_{\mathrm{L}} \quad\left[\mathrm{mol} \mathrm{m}_{\mathrm{r}}^{-3} \mathrm{~s}^{-1}\right] \\
& r_{2}=k_{2} \frac{K_{\mathrm{ads}, \mathrm{X}} K_{\mathrm{ads}, \mathrm{I}_{\text {het }}} C_{\mathrm{X}} C_{\mathrm{I}_{\text {het }}}}{\left(1+K_{\mathrm{ads}, \mathrm{I}_{\text {het }}} C_{\mathrm{I}_{\text {het }}}+K_{\mathrm{ads}, \mathrm{I}_{\mathrm{hom}}} C_{\mathrm{I}_{\mathrm{hom}}}+K_{\mathrm{ads}, \mathrm{X}} C_{\mathrm{X}}\right)^{2}} \frac{W_{\mathrm{cat}}}{V_{\mathrm{r}}} \\
& {\left[\mathrm{mol} \mathrm{m}_{\mathrm{r}}^{-3} \mathrm{~s}^{-1}\right. \text { ] }} \\
& r_{3}=k_{3}\left(C_{\mathrm{I}_{\text {het }}}-\frac{C_{\mathrm{I}_{\text {hom }}}}{K_{3}}\right) \varepsilon_{\mathrm{L}} \quad\left[\mathrm{mol} \mathrm{m}_{\mathrm{r}}^{-3} \mathrm{~s}^{-1}\right] \\
& r_{4}=k_{2} \frac{K_{\mathrm{ads}, \mathrm{X}} K_{\mathrm{ads}, \mathrm{I} \text { hom }} C_{\mathrm{X}} C_{\mathrm{I}_{\mathrm{hom}}}}{\left(1+K_{\mathrm{ads}, \mathrm{I}_{\mathrm{het}}} C_{\mathrm{I}_{\mathrm{het}}}+K_{\mathrm{ads}, \mathrm{I}_{\mathrm{hom}}} C_{\mathrm{I}_{\text {hom }}}+K_{\mathrm{ads}, \mathrm{X}} C_{\mathrm{X}}\right)^{2}} \frac{W_{\text {cat }}}{V_{\mathrm{r}}} \\
& {\left[\mathrm{mol} \mathrm{m}_{\mathrm{r}}^{-3} \mathrm{~s}^{-1}\right]} \\
& r_{5}=k_{\mathrm{D}} C_{\mathrm{A}} \varepsilon_{\mathrm{L}} \quad\left[\mathrm{mol} \mathrm{m}_{\mathrm{r}}^{-3} \mathrm{~s}^{-1}\right] \\
& r_{6}=k_{\mathrm{D}} C_{\mathrm{I}_{\mathrm{het}}} \varepsilon_{\mathrm{L}} \quad\left[\mathrm{mol} \mathrm{m}_{\mathrm{r}}^{-3} \mathrm{~s}^{-1}\right] \\
& r_{7}=k_{\mathrm{D}} C_{\mathrm{I}_{\mathrm{hom}}} \varepsilon_{\mathrm{L}} \quad\left[\mathrm{mol} \mathrm{m}_{\mathrm{r}}^{-3} \mathrm{~s}^{-1}\right]
\end{aligned}
$$

In eqs $1-7, \varepsilon_{\mathrm{L}}$ represents the liquid fraction, $W_{\text {cat }}$ the catalyst mass, and $V_{\mathrm{r}}$ the corresponding reactor volume.

Reactor Types and Model Equations. Reactor simulations were performed with in-house developed FORTRAN codes. The systems of differential and algebraic equations are solved using an open-source code, DASPK, as available from Netlib. ${ }^{18}$ The jet loop reactor, representing a low catalyst-toliquid ratio, consists of a reactor vessel and a non-negligible volume of tubing in the recirculation loop. The liquid phase is recycled at high flow rates through this loop and mixed with the gas before injection into the liquid in the reactor vessel, see also Figure 2a. In the trickle bed reactor, a high catalyst-to-liquid ratio reactor type, gas and liquid flow cocurrently over a fixed catalyst bed, as shown in Figure $2 \mathrm{~b}$. The mass balances are presented in the following sections. Isothermal operation is considered in order not to complicate the observations made. Moreover, temperature excursions would mainly enhance degradation reactions which are to be avoided anyway.

Jet Loop Reactor: Low Catalyst-to-Liquid Ratio. Overall, the jet loop reactor, see Figure 2a, operates as a batch reactor. The reactor is first loaded with all reactants and 
(a)

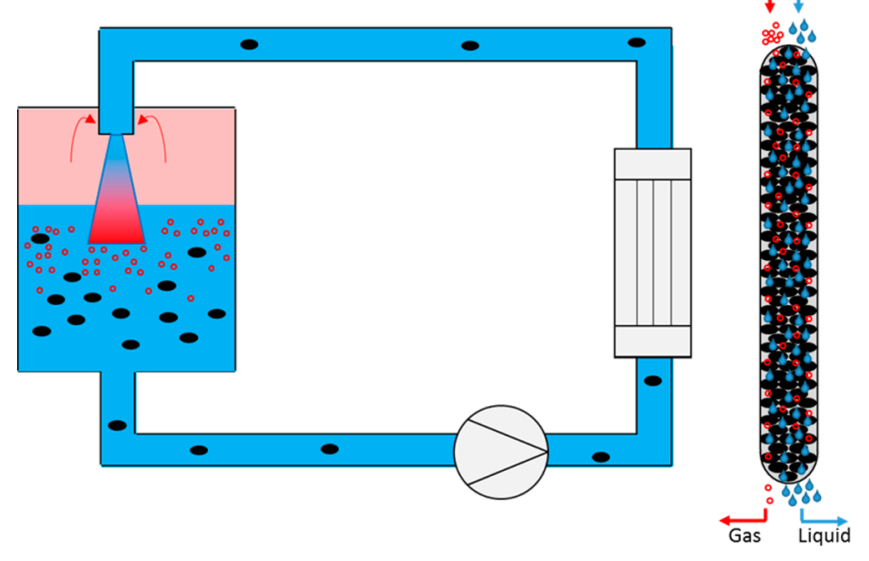

Figure 2. Representation of the reactor types: (a) jet loop reactor and (b) trickle bed reactor.

the catalyst. It is assumed that during the jet loop reactor operation, the catalyst is completely wetted and recirculates along with the liquid phase through the loop, at the same flow rate. The amount of liquid used is such that the loop is completely filled with the liquid and that sufficient liquid remains to occupy a significant volume fraction of the reactor vessel. The gas phase remains entirely in the reaction vessel, and only the fraction that is completely dissolved in the liquid phase flows through the loop.

For the purposes of this work, the jet loop reactor is modeled making use of the scheme shown in Figure 3. Because the jet

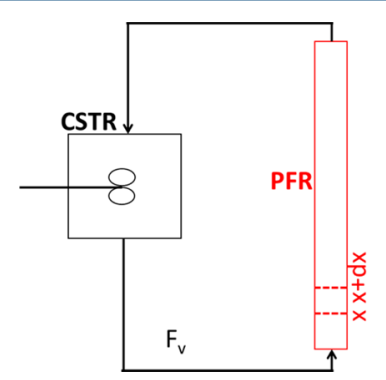

Figure 3. Schematic representation of the jet loop reactor for modeling purposes.

injectors used in these reactor types have high efficiencies and a high dissolution of the gas in the liquid is obtained, the reactor vessel can best be represented as a continuous stirred tank reactor (CSTR) for which the mass balance of component $j$ can be expressed as in eq 8 .

$$
\frac{\mathrm{d} n_{j}}{\mathrm{~d} t}=F_{j, \text { in }}-F_{j, \text { out }}+R_{j} V_{\mathrm{r}} \quad\left[\mathrm{mol} \mathrm{s}^{-1}\right]
$$

While $n_{j}$ represents the total amount of $j$, i.e., in the gas and liquid phase, all other terms in eq 8 are related to the liquid phase. The gas phase remains in the reactor vessel and is simulated to be in thermodynamic equilibrium with the liquid phase owing to the reported high mixing efficiencies and correspondingly high mass-transfer coefficients. The corresponding simulation results may be slightly different from reality, but simulating this case is also very advantageous as the observed phenomena are not masked by mass transfer and can be directly related to the operating conditions. The initial condition corresponding to eq 8 is shown in eq 9 .

$$
n_{j}(t=0)=n_{j}^{0} \quad[\mathrm{~mol}]
$$

The loop is modeled as a plug flow reactor (PFR) for which the corresponding mass balance of a component $j$ is shown in eq 10 .

$$
\varepsilon_{\mathrm{L}} \frac{\partial C_{j}}{\partial t}=-v_{x} \frac{\partial C_{j}}{\partial x}+R_{j} \quad\left[\mathrm{molm}_{\mathrm{r}}^{-3} \mathrm{~s}^{-1}\right]
$$

The initial condition required for eq 10 expresses that the loop is completely filled with liquid and therein suspended catalyst, see eq 11. The boundary condition stems from the effluent of the reactor vessel, as shown in eq 12 .

$$
\begin{aligned}
& C_{j}(t=0)=C_{j}^{0} \quad\left[\mathrm{~mol} \mathrm{~m}_{\mathrm{L}}^{-3}\right] \\
& C_{j}(x=0)=C_{j, \text { CSTR }} \quad\left[\mathrm{mol} \mathrm{m}_{\mathrm{L}}^{-3}\right]
\end{aligned}
$$

Density changes, resulting in a velocity profile in the tubing, are captured using eq 13 expressing the total mass balance, an equation that has already been applied to, for example, modeling of loop polymerizations: ${ }^{19}$

$$
\frac{\partial v_{x}}{\partial x}=\sum_{j=1}^{n} \frac{\mathrm{MM}_{j} R_{j}}{\rho_{j}} \quad\left[\mathrm{~m}_{\mathrm{L}}^{3} \mathrm{~m}_{\mathrm{r}}^{-3} \mathrm{~s}^{-1}\right]
$$

The superficial liquid velocity stems from the flow rate $F_{\mathrm{V}}$ imposed by the pump in the loop, see eq 14, the latter being the boundary condition corresponding to eq 13 .

$$
v_{x}\left(x=x_{\text {Pump }}\right)=\frac{F_{\mathrm{V}}}{\Omega} \quad\left[\mathrm{m}_{\mathrm{L}}^{3} \mathrm{~m}_{\mathrm{r}}^{-2} \mathrm{~s}^{-1}\right]
$$

Simulations have shown that the variation of the superficial liquid velocity resulting from density changes is very limited ( $\ll 1 \%)$, and this hence justifies that the superficial liquid velocity can be placed before the differential term on the righthand side in eq 10.

Trickle Bed Reactor: High Catalyst-to-Liquid Ratio. The second reactor type considered in the present work is a trickle bed reactor, see Figure $2 \mathrm{~b}$. It is a continuous flow reactor with a high catalyst-to-liquid ratio. The steady-state mass balance for a component $j$ can be written as in eqs 15 and 16 for the gas and liquid phase, respectively.

$$
\begin{aligned}
& \frac{\mathrm{d} F_{j}^{\mathrm{G}}}{\mathrm{d} V_{\mathrm{r}}}=-k_{\mathrm{GL}, j} a_{\mathrm{GL}} \varepsilon_{\mathrm{cat}}\left(\frac{C_{j}^{\mathrm{G}}}{H_{j}}-C_{j}^{\mathrm{L}}\right) \quad\left[\mathrm{mol} \mathrm{m}_{\mathrm{r}}^{-3} \mathrm{~s}^{-1}\right] \\
& \frac{\mathrm{d} F_{j}^{\mathrm{L}}}{\mathrm{d} V_{\mathrm{r}}}=k_{\mathrm{GL}, j} a_{\mathrm{GL}} \varepsilon_{\mathrm{cat}}\left(\frac{C_{j}^{\mathrm{G}}}{H_{j}}-C_{j}^{\mathrm{L}}\right)+R_{j} \quad\left[\mathrm{~mol} \mathrm{~m}_{\mathrm{r}}^{-3} \mathrm{~s}^{-1}\right]
\end{aligned}
$$

The right-hand side of eq 16, hence, has a term that describes interphase mass transfer and a reaction rate term that describes both homogeneous bulk liquid phase and heterogeneously catalyzed reactions. The inlet flow rates are the boundary conditions required to solve the set of eqs 15 and 16 (see eqs 17 and 18).

$$
\begin{aligned}
& F_{j}^{\mathrm{G}}\left(V_{\mathrm{r}}=0\right)=F_{j}^{\mathrm{G}, 0} \quad\left[\mathrm{~mol} \mathrm{~s}^{-1}\right] \\
& F_{j}^{\mathrm{L}}\left(V_{r}=0\right)=F_{j}^{\mathrm{L}, 0} \quad\left[\mathrm{~mol} \mathrm{~s}^{-1}\right]
\end{aligned}
$$


The catalyst pellets are assumed to be fully wetted in the range of investigated operating conditions. The gas- and liquidside mass-transfer coefficients are calculated at every value of the axial coordinate based on the correlations of Wild and Sato, respectively. $^{20,21}$ The overall gas-liquid mass-transfer coefficient is then calculated based on the two-resistance model. ${ }^{22}$ In the full range of investigated operating conditions the trickle flow regime was verified using the flow regime map of Fukushima and Kusaka. ${ }^{23}$

Definitions. The simulation results are quantified in terms of reactant A conversion and product selectivities. Equation 19 defines the conversion of $\mathrm{A}$ :

$$
X_{\mathrm{A}}=\frac{n_{\mathrm{A}}^{0}-n_{\mathrm{A}}}{n_{\mathrm{A}}^{0}} \quad\left[\mathrm{~mol} \mathrm{~mol}^{-1}\right]
$$

The selectivity toward product $j$ obtained from reactant $A$ is calculated using Equation 20:

$$
S_{j, \mathrm{~A}}=\frac{N_{j}\left(n_{j}-n_{j}^{0}\right)}{2\left(n_{\mathrm{A}}^{0}-n_{\mathrm{A}}\right)} \quad\left[\mathrm{mol} \mathrm{mol}^{-1}\right]
$$

The factor 2 in eq 20 arises from the stoichiometric coefficients in reaction 1 , see also Figure $1 . N_{j}$ relates to these stoichiometric coefficients and is 1 for $\mathrm{P}_{\text {het }}, \mathrm{P}_{\text {hom }}, \mathrm{I}_{\text {het, } \mathrm{D}}$, and $I_{\text {hom }, D}$ and 2 for $A_{D}$. No distinction is made between the individual degradation products, i.e., only the sum of their selectivities is considered: $S_{\mathrm{D}, \mathrm{A}}=S_{\mathrm{I}_{\mathrm{het}} \mathrm{D}, \mathrm{A}}+S_{\mathrm{I}_{\mathrm{hom} m} \mathrm{D}, \mathrm{A}}+S_{\mathrm{A}, \mathrm{D}, \mathrm{A}}$. The yield of product $j$ obtained from reactant $A$ is defined as the selectivity times the conversion, as in eq 21 .

$$
Y_{j, \mathrm{~A}}=\frac{N_{j}\left(n_{j}-n_{j}^{0}\right)}{2 n_{\mathrm{A}}^{0}} \quad\left[\mathrm{~mol} \mathrm{~mol}^{-1}\right]
$$

\section{REACTOR SIMULATIONS}

Large-scale reactor simulations were performed to assess the effects of varying the operating conditions on the product spectrum. In this work the $\mathrm{B} / \mathrm{A}$ ratio, the $\mathrm{X} / \mathrm{A}$ ratio, and the total pressure were varied. In addition, the catalyst mass suspended in the jet loop reactor was also varied, while the effect of varying the total feed flow rate on the product spectrum was examined in the trickle bed reactor. The variation of these equal or similar operating conditions might be less relevant in one of the reactors compared to the other one; nevertheless, the simulation results are such that they can be directly compared from one reactor type to the other.

Jet Loop Reactor. The reactor vessel and the loop have a volume of 4.75 and $0.63 \mathrm{~m}^{3}$ respectively and is at present used commercially, for reactions such as aminations, with a typical annual production of 1-2 kton/year. All simulations were performed at conditions where the vapor pressure of the volatile reactant $\mathrm{B}$ amounts to $2.2 \mathrm{MPa}$. The volumetric flow rate imposed by the pump in the loop amounts to $250 \mathrm{~m}^{3} \mathrm{~h}^{-1}$. The reactant $\mathrm{A}$ is always diluted 30 -fold in the solvent. The simulations are performed with an initial amount of liquid in the reactor of approximately $3.75 \mathrm{~m}^{3}$.

The composition of the mixture in the jet loop reactor is presented in Figure 4 for the reference case.

The homogeneous product is clearly the most abundant product in the jet loop reactor. The latter could be expected based on the catalyst-to-liquid ratio, which is low for this reactor type; hence, bulk liquid-phase reactions are favored. It

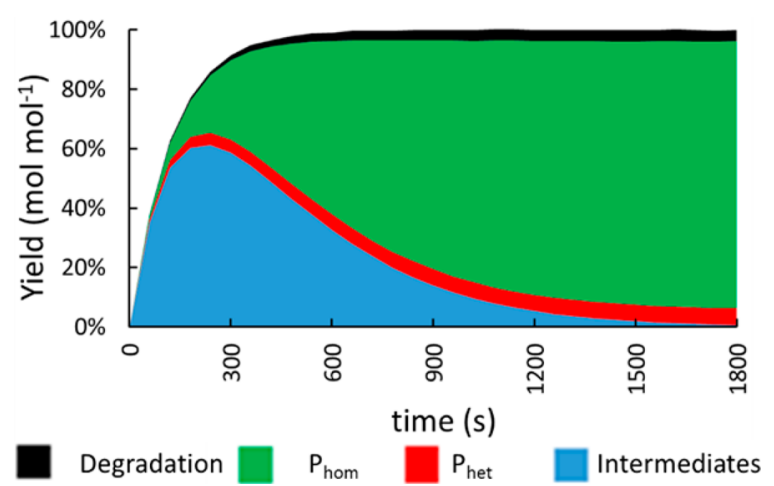

Figure 4. Molar heterogeneous $\left(\mathrm{P}_{\text {het }}\right)$ and homogeneous $\left(\mathrm{P}_{\text {hom }}\right)$ product yields as a function of time in the jet loop reactor for the reference case $\left(n_{\mathrm{A}}{ }^{0}=1300 \mathrm{~mol}, \mathrm{~B} / \mathrm{A}=20, \mathrm{X} / \mathrm{A}=30, p=7.5 \mathrm{MPa}\right.$, $W_{\text {cat }}=60 \mathrm{~kg}$ ). Product yields were calculated using model simulated compositions from eqs $8-14$ and the parameters shown in Table 1.

can be clearly seen from Figure 4 that full conversion of A, mainly to the intermediates, is reached quite rapidly. The latter are subsequently converted to the homogeneous product with a $90 \%$ yield, apart from a $6 \%$ yield toward the heterogeneous product and $4 \%$ of degradation products.

The effect of increasing the $\mathrm{B} / \mathrm{A}$ ratio, in the jet loop reactor corresponding to a decrease in the initial amount of $\mathrm{A}$ to maintain the initial amount of liquid in the reactor, from 10 to 40 is shown in Figure 5a. The heterogeneous product yield increases from $3 \%$ to $12 \%$, and the yield of the degradation products decreases from $8 \%$ to $2 \%$. The yield of the homogeneous product initially increases by $1.5 \%$ to a maximum value of $91 \%$ but subsequently decreases again as the B/A ratio exceeds 20 , with a $86 \%$ yield being reached at a B/A ratio of 40 . Several phenomena contribute to the observed yield changes. First, as the B/A ratio increases, $r_{1}$ is relatively increased compared to degradation of $\mathrm{A}$. In general the liquid concentration of $\mathrm{A}$ and the intermediates is lower, which leads to lower degradation rates. In addition, the ratio of the catalyst to A increases such that the heterogeneously catalyzed reactions are more favored. At a $\mathrm{B} / \mathrm{A}$ ratio up to 20 this results in both increased yields of $\mathrm{P}_{\text {het }}$ and $\mathrm{P}_{\text {hom }}$ while there is significant competition between the conversion of $\mathrm{I}_{\text {het }}$ to $\mathrm{I}_{\text {hom }}$ $\left(r_{3}\right)$ and to $\mathrm{P}_{\text {het }}\left(r_{2}\right)$ at higher $\mathrm{B} / \mathrm{A}$ ratios. Hence, the heterogeneous product yield continuously increases while the homogeneous product yield decreases at a B/A ratio exceeding 20.

Varying the ratio of $\mathrm{X} / \mathrm{A}$ has a small effect on the product spectrum, as can be seen in Figure $5 \mathrm{~b}$. The homogeneous product yield is $90 \%$ in both cases, while the heterogeneous product yield increases by $1 \%$ on decreasing the $\mathrm{X} / \mathrm{A}$ ratio, and correspondingly the amount of degradation reactions is decreased. This can be explained by the vapor-liquid equilibrium as the fraction of $\mathrm{B}$ in the liquid phase increases from $34 \%$, when $X / A=30$, to $36 \%$, when $X / A=10$, and the corresponding increase in the reaction rate $r_{1}$.

A total pressure increase, as shown in Figure 5c, has a similar but even less pronounced effect on the liquid fraction of $\mathrm{B}$ as decreasing the $\mathrm{X} / \mathrm{A}$ ratio. Hence, only slight yield increases in heterogeneous product and decreases in degradation products are observed with varying the pressure.

Increasing the catalyst mass significantly reduces the amount of degradation products, thus favoring the formation of $\mathrm{P}_{\text {hom }}$ and $\mathrm{P}_{\text {het }}$ (see Figure 5d). As was shown in our previous work, 

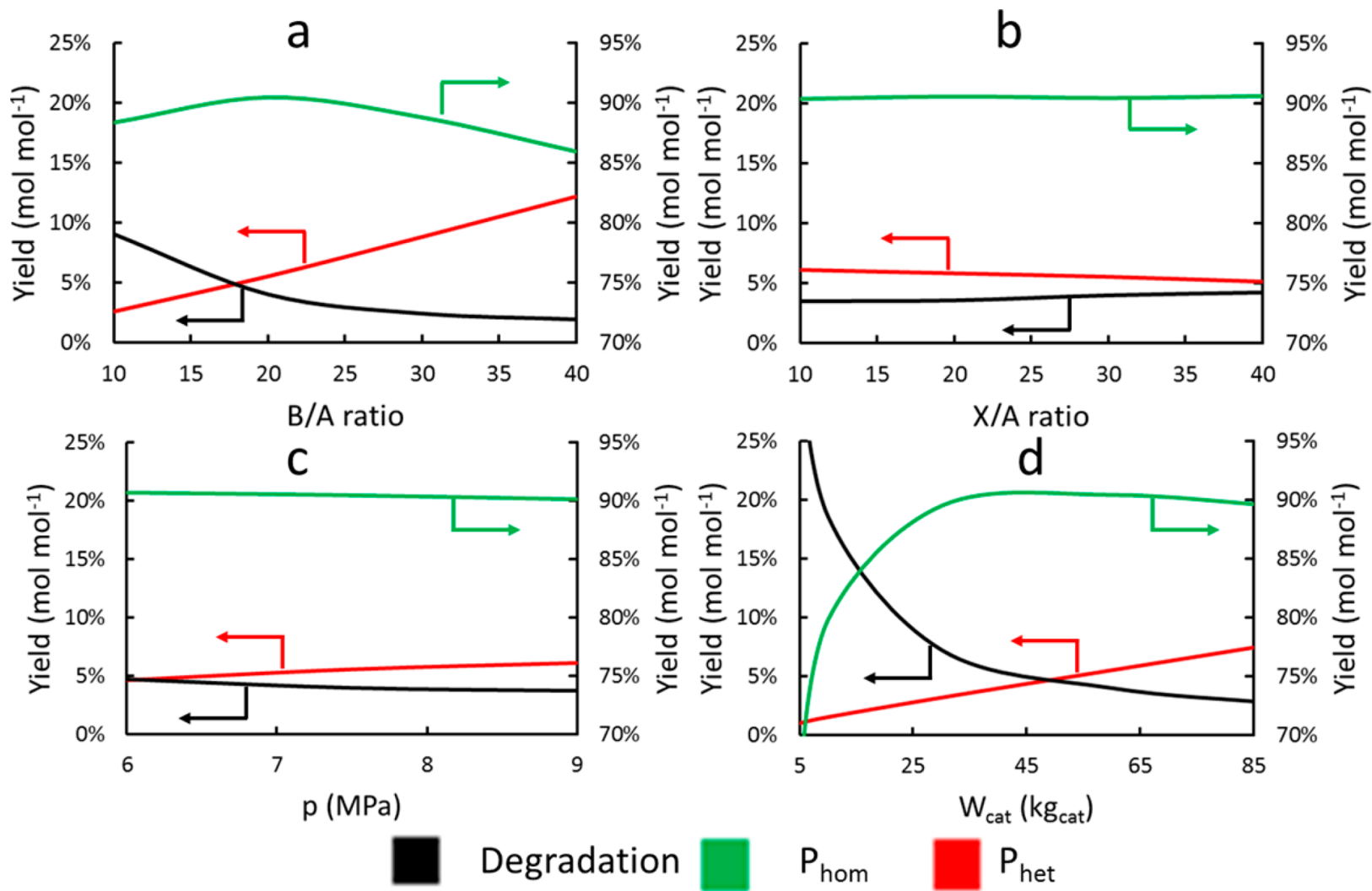

Figure 5. Molar heterogeneous $\left(\mathrm{P}_{\text {het }}\right)$ and homogeneous $\left(\mathrm{P}_{\text {hom }}\right)$ product yields as a function of varying operating conditions in the jet loop reactor. (a) Variation of the $\mathrm{B} / \mathrm{A}$ ratio while $\mathrm{X} / \mathrm{A}=30, p=7.5 \mathrm{MPa}, \mathrm{W}_{\text {cat }}=60 \mathrm{~kg}$, (b) Variation of the $\mathrm{X} / \mathrm{A}$ ratio while $\mathrm{B} / \mathrm{A}=20, p=7.5 \mathrm{MPa}, \mathrm{W}_{\text {cat }}=60 \mathrm{~kg}$, (c) Variation of the total pressure while $\mathrm{B} / \mathrm{A}=20, \mathrm{X} / \mathrm{A}=30, \mathrm{~W}_{\text {cat }}=60 \mathrm{~kg}$, (d) Variation of the catalyst mass while $\mathrm{B} / \mathrm{A}=20, \mathrm{X} / \mathrm{A}=30, p=7.5$ $\mathrm{MPa}$. Product yields were calculated using model simulated compositions from eqs $8-14$ and the parameters shown in Table 1 .

the yield of the homogeneous product exhibits a broad maximum as a function of the catalyst amount while the heterogeneous product yield steadily increases.

Trickle Bed Reactor. A continuous flow reactor with a diameter of $1 \mathrm{~m}$ and a length of $4 \mathrm{~m}$ was selected for this work. These values allow for flexibility in the trickle flow regime while similar optimal product yields can be achieved on a yearly basis compared to the jet loop reactor with a limited number of tubes. The bulk density of the catalyst bed $\rho_{\text {bed }}$ defined as $W_{\text {cat }} /$ $V_{\mathrm{r}}$, is assumed to be $1000 \mathrm{~kg}_{\text {cat }} \mathrm{m}_{\mathrm{r}}^{-3}$, and the reactant $\mathrm{A}$ is diluted 30 -fold in the solvent.

The composition of the mixture as a function of the axial coordinate $x$ is presented in Figure 6 for the reference case.

From Figure 6 it can be observed that the heterogeneous product is the most abundantly obtained one, besides a significant amount of homogeneous product and only a marginal fraction of degradation products. The presence of a significant amount of homogeneous product is, at least partially, counterintuitive for a reactor with a high catalyst-to-liquid ratio. At the investigated operating conditions the heterogeneous product yield amounts to $60 \%$, while that of the homogeneous product remains as high as $40 \%$. This unexpected observation stems from pronounced mass-transfer limitations for the gaseous reactant $\mathrm{X}$ to the liquid phase. Instead, the mass transfer is somewhat slower than the rate at which $\mathrm{X}$ reacts with $I_{\text {het }}$ to $P_{\text {het }}$. Hence, in the liquid phase being poor in $X, I_{\text {het }}$ is rather further converted to $I_{\text {hom }}$ and, ultimately, to $P_{\text {hom }}$.

When the B/A ratio is increased, see Figure $7 \mathrm{a}$, the yield of the heterogeneous product exhibits a minimum and then increases, whereas the yield of the homogeneous product

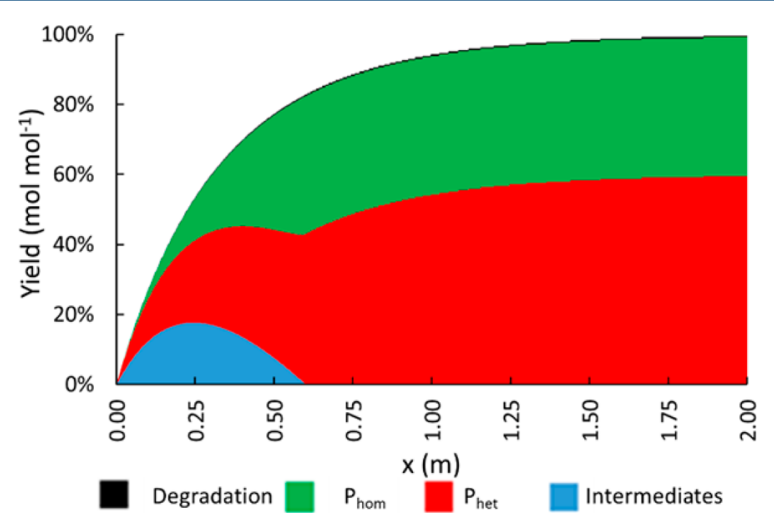

Figure 6. Molar heterogeneous $\left(P_{\text {het }}\right)$ and homogeneous $\left(P_{\text {hom }}\right)$ product yields as a function of the axial coordinate in the trickle bed reactor for the reference case $\left(F_{\mathrm{A}}{ }^{0}=1.25 \times 10^{-1} \mathrm{~mol} \mathrm{~s}^{-1}, \mathrm{~B} / \mathrm{A}=20\right.$, $\mathrm{X} / \mathrm{A}=30, p=7.5 \mathrm{MPa}$ ) Product yields were calculated using model simulated compositions from eqs $15-18$ and the parameters shown in Table 1.

exhibits a maximum and, subsequently, decreases. The latter maximum was also observed in the jet loop reactor while the minimum in heterogeneous product yield was not. The presence of a higher amount of B and hence also a higher gas flow rate results in an enhanced gas-liquid mass-transfer coefficient, explaining why more heterogeneous product is formed at a higher B/A ratio in the trickle bed reactor while suppression of degradation was the main effect in the jet loop reactor. 

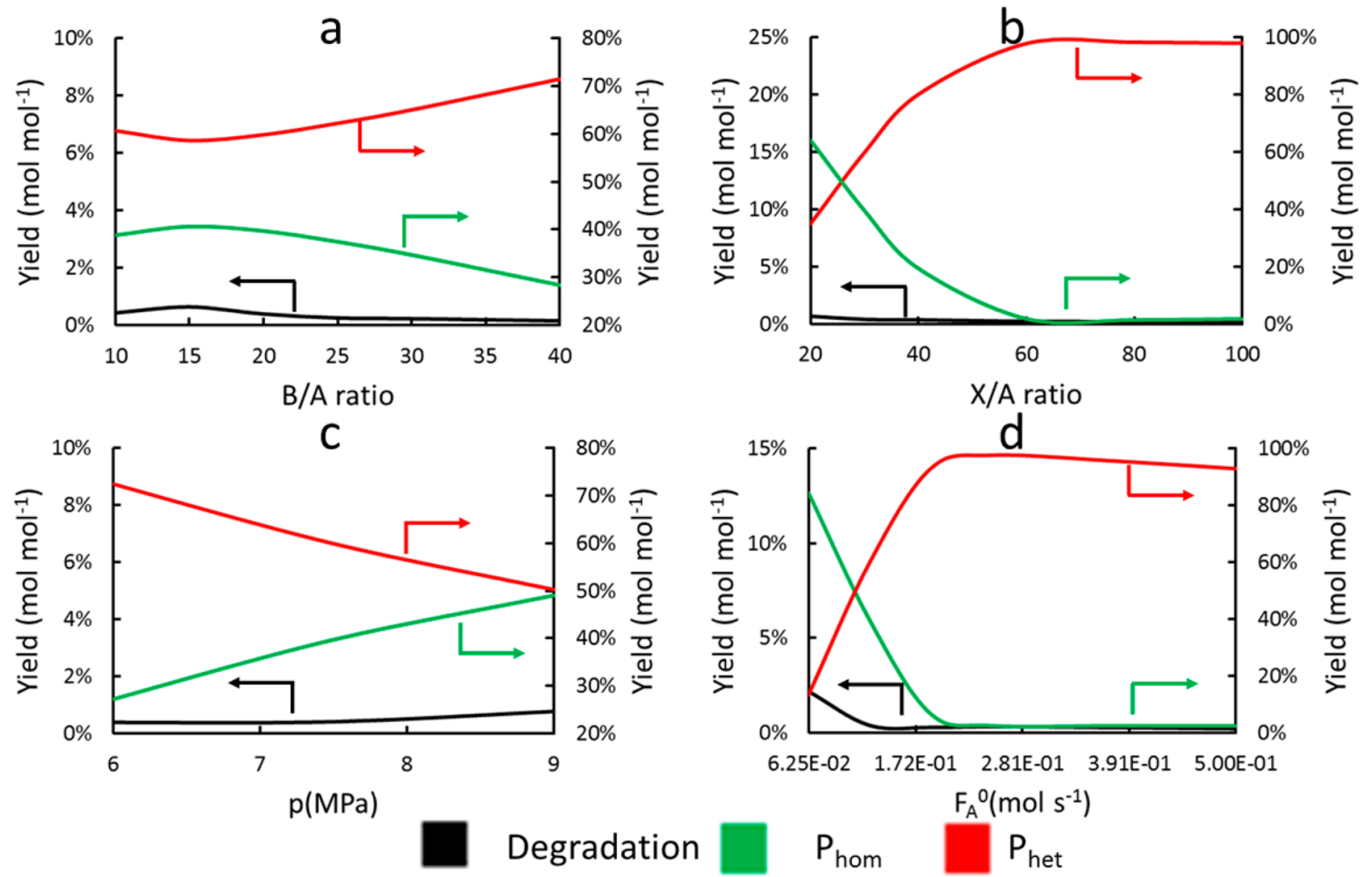

Figure 7. Molar heterogeneous $\left(\mathrm{P}_{\text {het }}\right)$ and homogeneous $\left(\mathrm{P}_{\text {hom }}\right)$ product yields as a function of varying operating conditions in the trickle bed reactor. (a) Variation of the $\mathrm{B} / \mathrm{A}$ ratio while $F_{\mathrm{A}}{ }^{0}=1.25 \times 10^{-1} \mathrm{~mol} \mathrm{~s}^{-1}, \mathrm{X} / \mathrm{A}=30, p=7.5 \mathrm{MPa}$; (b) variation of the $\mathrm{X} / \mathrm{A}$ ratio while $F_{\mathrm{A}}{ }^{0}=1.25 \times$ $10^{-1} \mathrm{~mol} \mathrm{~s}^{-1}, \mathrm{~B} / \mathrm{A}=20, p=7.5 \mathrm{MPa}$; (c) variation of the total pressure while $F_{\mathrm{A}}{ }^{0}=1.25 \times 10^{-1} \mathrm{~mol} \mathrm{~s}{ }^{-1}, \mathrm{~B} / \mathrm{A}=20, \mathrm{X} / \mathrm{A}=30$; (d) variation of the feed flow rate while $\mathrm{B} / \mathrm{A}=20, \mathrm{X} / \mathrm{A}=30, p=7.5 \mathrm{MPa}$. Product yields were calculated using model simulated compositions from eqs $15-18$ and the parameters shown in Table 1 .

A similar, and much more pronounced, effect is observed when the X/A ratio is increased, as shown in Figure $7 \mathrm{~b}$. The yield of $\mathrm{P}_{\text {het }}$ then increases to $80 \%$ while the yield of $\mathrm{P}_{\text {hom }}$ drops to $19 \%$ when the $\mathrm{X} / \mathrm{A}$ ratio is increased to 40 . A further increase of this $\mathrm{X} / \mathrm{A}$ ratio to 100 results in a further increased yield of $\mathrm{P}_{\text {het }}$ as a consequence of the strongly, by a factor of 2 for the gaseous reactant $\mathrm{X}$ and higher for, e.g. $\mathrm{B}$, enhanced gasliquid mass transfer, with a yield of the latter heterogeneous product amounting to no less than $98 \%$. In the jet loop reactor the change in $\mathrm{B}$ concentration was the predominant effect of varying the $\mathrm{X} / \mathrm{A}$ ratio resulting in lower heterogeneous product yields at higher $\mathrm{X} / \mathrm{A}$ ratios. In the trickle bed, on the other hand, the enhanced gas-liquid mass transfer is the main effect of increasing the X/A ratio, resulting in increased heterogeneous product yields.

A pressure increase results in a decrease of the heterogeneous product yield and a corresponding increase of the homogeneous product yield (see Figure 7c). The overall gas-liquid mass-transfer coefficient for $\mathrm{X}$ increases with the pressure; thus, it would be expected that the heterogeneous product would be more favored. As described for the jet loop reactor, the pressure increase also results in a larger fraction of the volatile reactant $B$ in the liquid phase. In this case, the mole fraction of B in the liquid phase increases at the expense of the solvent, resulting in a significant increase of $r_{1}$. Therefore, the concentration of $\mathrm{I}_{\text {het }}$ is so abundant that even the higher amount of $\mathrm{X}$ transferred to the liquid phase is not enough to shift the product spectrum toward $\mathrm{P}_{\text {het }}$.
Figure $7 \mathrm{~d}$ shows the effect of varying the feed flow rate of $\mathrm{A}$ while keeping all ratios constant, and hence varying the total gas and liquid flow rate, within the trickle flow regime. The selectivity shift from the homogeneous product to the heterogeneous product is immediately evident. Both the increase in B in the liquid phase and, especially, the increase of the overall gas-liquid mass-transfer coefficient for $\mathrm{X}$ are significant. The former explains the initial buildup of intermediates and formation of some $\mathrm{P}_{\text {hom }}$ up to a certain point, after which no more intermediates are present. The remainder of $A$ is then converted to $I_{\text {het }}$ and directly to $P_{\text {het }}$. Ultimately, the transfer of $\mathrm{X}$ becomes sufficiently fast to selectively produce $\mathrm{P}_{\text {het }}$. The optimum $\mathrm{P}_{\text {het }}$ yield in Figure $7 \mathrm{~d}$ can be explained by the incomplete conversion of the reactant $A$ at the highest feed rates.

Comparison of the Different Reactors and Overall Product Spectrum Optimization. Product yields, under realistic conditions, in the jet loop reactor are always toward the homogeneous product and do not vary greatly. The aim when selecting this reactor clearly has to be the optimization of the $\mathrm{P}_{\text {hom }}$ yield and, apart from that, suppressing the formation of degradation products. Several sets of operating conditions resulted in a $\mathrm{P}_{\text {hom }}$ yield of $91 \%$, along with $5 \% \mathrm{P}_{\text {het }}$.

The simulated trickle bed reactor behavior is more complex. The heterogeneously catalyzed reaction steps are favored as long as the overall gas-liquid mass transfer of the gaseous reactant is not limiting. A combination of a higher flow rate of $\mathrm{A}$ at the lowest operating pressure with elevated $\mathrm{B} / \mathrm{A}$ and $\mathrm{X} / \mathrm{A}$ ratios results in $98 \% \mathrm{P}_{\text {het }}$ yield and $1 \% \mathrm{P}_{\text {hom }}$ (see Figure $8 \mathrm{a}$ ). 

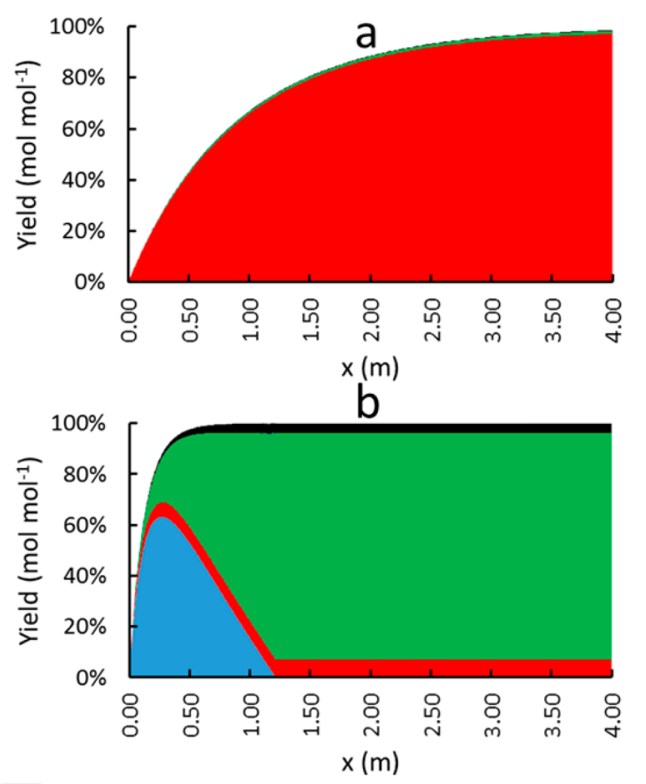

Degradation $\square P_{\text {hom }} \square P_{\text {het }} \square$ Intermediates

Figure 8. Molar heterogeneous $\left(\mathrm{P}_{\text {het }}\right)$ and homogeneous $\left(\mathrm{P}_{\text {hom }}\right)$ product yields as a function of the axial coordinate in the trickle bed reactor: (a) maximal heterogeneous product yield $\left(F_{\mathrm{A}}{ }^{0}=2.5 \times 10^{-1}\right.$ mol s$\left.{ }^{-1}, \mathrm{~B} / \mathrm{A}=40, \mathrm{X} / \mathrm{A}=60, p=6.0 \mathrm{MPa}\right)$ and $(\mathrm{b})$ maximal homogeneous product yield $\left(\mathrm{F}_{\mathrm{A}}{ }^{0}=6.25 \times 10^{-2} \mathrm{~mol} \mathrm{~s}^{-1}, \mathrm{~B} / \mathrm{A}=10, \mathrm{X} /\right.$ $\mathrm{A}=20, p=9.0 \mathrm{MPa})$. Product yields were calculated using model simulated compositions from eqs $15-18$ and the parameters shown in Table 1.

More challenging is the optimization of the $\mathrm{P}_{\text {hom }}$ yield in a trickle bed reactor. The latter can be achieved at lower flow rates of $\mathrm{A}$ at the highest operating pressure and lower $\mathrm{B} / \mathrm{A}$ and $\mathrm{X} / \mathrm{A}$ ratios resulting in a $89 \% \mathrm{P}_{\text {hom }}$ yield and $7 \%$ of $\mathrm{P}_{\text {het }}$ (see Figure 8b). Also, a non-negligible amount of degradation products is present in the reaction mixture. Note that this maximum $\mathrm{P}_{\text {hom }}$ yield approaches that obtained in the jet loop reactor. The trickle bed reactor hence allows a broader variety of product spectra because gas-liquid mass-transfer limitations can be avoided or, on the contrary, exploited to tune the product spectrum either way. This tuning is possible only as long as the trickle bed reactor does not have a high length-todiameter ratio. Optimal exploitation of such a reactor would lead to higher flow rates and thus enhanced mass transfer which, ultimately, will always result in high heterogeneous product selectivities. Accounting for the exothermicity of glucose reductive aminolysis could lead to degradation reactions becoming more pronounced. The latter is expected to be especially so for the trickle bed reactor because of more challenging temperature control.

\section{CONCLUSIONS}

Reactor simulations for a bimodal reaction sequence including degradation reactions allow the interpretation and optimization of homogeneous and heterogeneous product yields. While higher homogeneous product yields are typically obtained in a reactor with a low catalyst-to-liquid ratio such as a jet loop reactor, a trickle bed reactor configuration easily allows the optimization of the heterogeneous product yield. The inherent efficient mixing in the CSTR section of the jet loop reactor limits the flexibility in the product yields that can be obtained with this reactor. The homogeneous product is always obtained in the highest amounts, and the focus of an optimization study for this reactor is primarily to reduce the extent of degradation products and second to reduce the extent of product loss through the formation of heterogeneous product. On the other hand, in a reactor with a high catalyst-to-liquid ratio such as a trickle bed reactor, the product spectrum can be tuned to a greater extent. Mass-transfer limitations of the gaseous reactant directly interfere in the reaction rates of the heterogeneously catalyzed steps. Maximization of the mass transfer, mainly by increasing the feed flow rate of the gaseous reactant, will result in a very high heterogeneous product yield, up to $99 \%$ in the best case. Reducing this flow rate can completely shift the product spectrum toward the homogeneous product. In this case the goal is again to reduce the amount of degradation reactions and the extent to which heterogeneous product is being formed, rendering the challenge similar to operating the jet loop reactor.

\section{AUTHOR INFORMATION}

\section{Corresponding Author}

*E-mail: Joris.Thybaut@UGent.be.

\section{ORCID}

Joris W. Thybaut: 0000-0002-4187-7904

Guy B. Marin: 0000-0002-6733-1213

\section{Notes}

The authors declare no competing financial interest.

\section{ACKNOWLEDGMENTS}

This work was supported by Flanders Innovation \& Entrepreneurship VLAIO (IWT) via the intermediary of FISCH/CATALISTI, contract 145020 - Carboleum.

\section{NOTATION}

\section{Roman Letters}

$a_{\mathrm{GL}}=$ interfacial area $\mathrm{m}_{\mathrm{i}}^{2} \mathrm{~m}_{\text {bed }}{ }^{-3}$

$C_{j}=$ liquid concentration of component $j, \mathrm{~mol} \mathrm{~m}_{\mathrm{L}}{ }^{-3}$

$F_{j}=$ molar flow rate of component $j, \mathrm{~mol} \mathrm{~s}^{-1}$

$F_{\mathrm{v}}=$ volumetric flow rate imposed by the pump, $\mathrm{m}_{\mathrm{L}}{ }^{3} \mathrm{~s}^{-1}$

$H_{j}=$ Henry's constant of component $j, \mathrm{~m}_{\mathrm{L}}{ }^{3} \mathrm{~m}_{\mathrm{G}}{ }^{-3}$

$k_{i}=$ rate coefficient of reaction $i, \mathrm{~m}^{3} \mathrm{~mol}^{-1} \mathrm{~s}^{-1}$ or mol kg ${ }_{\text {cat }}^{-1} \mathrm{~s}^{-1}$ or $\mathrm{s}^{-1}$

$k_{\mathrm{GL}, j}=$ overall gas-liquid mass-transfer coefficient of component $j, \mathrm{~m}_{\mathrm{L}}{ }^{3} \mathrm{~m}_{\mathrm{i}}^{-2} \mathrm{~s}^{-1}$

$K_{i}=$ thermodynamic equilibrium coefficient of reaction $i,-$

$K_{\mathrm{ads}, j}=$ adsorption equilibrium coefficient of component $j$, $\mathrm{m}_{\mathrm{L}}^{3} \mathrm{~mol}^{-1}$

$\mathrm{MM}_{j}=$ molar mass of component $j, \mathrm{~kg} \mathrm{~mol}^{-1}$

$n_{j}=$ molar amount of component $j$, mol

$N_{j}=$ stoichiometric correction factor, -

$r_{i}=$ reaction rate of reaction $i, \mathrm{~mol} \mathrm{~m}_{\mathrm{r}}^{-3} \mathrm{~s}^{-1}$

$R_{j}=$ net rate of formation of component $j, \mathrm{~mol} \mathrm{~m}_{\mathrm{r}}{ }^{-3} \mathrm{~s}^{-1}$

$S_{j, \mathrm{~A}}=$ selectivity toward product $j$ originating from reactant

$\mathrm{A}, \mathrm{mol} \mathrm{mol}{ }^{-1}$

$t=$ batch time, $\mathrm{s}$

$v_{x}=$ axial velocity in the $x$ direction, $\mathrm{m}_{\mathrm{L}}{ }^{3} \mathrm{~m}_{\mathrm{r}}{ }^{-2} \mathrm{~s}^{-1}$

$V_{\mathrm{r}}=$ reactor volume, $\mathrm{m}_{\mathrm{r}}{ }^{3}$

$W_{\text {cat }}=$ catalyst mass, $\mathrm{kg}_{\text {cat }}$

$X_{\mathrm{A}}=$ conversion of the reactant $\mathrm{A}, \mathrm{mol} \mathrm{mol}^{-1}$

$Y_{j, \mathrm{~A}}=$ yield toward product $j$ originating from reactant $\mathrm{A}$, $\mathrm{mol} \mathrm{mol}{ }^{-1}$ 


\section{Greek Letters}

$\varepsilon_{\mathrm{L}}=$ liquid fraction, $\mathrm{m}_{\mathrm{L}}^{3} \mathrm{~m}_{\mathrm{r}}^{-3}$

$\varepsilon_{\text {cat }}=$ catalyst bed fraction, $\mathrm{m}_{\text {bed }}{ }^{3} \mathrm{~m}_{\mathrm{r}}{ }^{-3}$

$\rho_{j}=$ density of component $j, \mathrm{~kg} \mathrm{~m}_{\mathrm{L}}{ }^{-3}$

$\Omega=$ cross-sectional area of the loop, $\mathrm{m}_{\mathrm{r}}^{2}$

\section{Subscripts}

in $=$ inlet

out $=$ outlet

\section{Superscripts}

$0=$ initial

$\mathrm{G}=$ gas

$\mathrm{L}=$ liquid

\section{REFERENCES}

(1) Mignonac, G. Nouvelle méthode générale de préparation des amines à partir des aldéhydes ou des cétones. Compt. Rend. 1921, 172, 223-225.

(2) Gomez, S.; Peters, J. A.; Maschmeyer, T. The reductive amination of aldehydes and ketones and the hydrogenation of nitriles: mechanistic aspects and selectivity control. Adv. Synth. Catal. 2002, 344, 1037-1058.

(3) Bähn, S.; Imm, S.; Neubert, L.; Zhang, M.; Neumann, H.; Beller, M. The Catalytic Amination of Alcohols. ChemCatChem 2011, 3, $1853-1864$.

(4) Hayes, K. S. Industrial processes for manufacturing amines. Appl. Catal., A 2001, 221, 187-195.

(5) Reyes, S. C.; Iglesia, E.; Kelkar, C. P. Kinetic-transport models of bimodal reaction sequences-I. Homogeneous and heterogeneous pathways in oxidative coupling of methane. Chem. Eng. Sci. 1993, 48, 2643-2661.

(6) Kechagiopoulos, P. N.; Thybaut, J. W.; Marin, G. B. Oxidative Coupling of Methane: A Microkinetic Model Accounting for Intraparticle Surface-Intermediates Concentration Profiles. Ind. Eng. Chem. Res. 2014, 53, 1825-1840.

(7) Beltrán, F. J.; Rivas, F. J.; Montero-de-Espinosa, R. Catalytic ozonation of oxalic acid in an aqueous $\mathrm{TiO} 2$ slurry reactor. Appl. Catal., B 2002, 39, 221-231.

(8) Di Serio, M.; Tesser, R.; Santacesaria, E. Comparison of Different Reactor Types Used in the Manufacture of Ethoxylated, Propoxylated Products. Ind. Eng. Chem. Res. 2005, 44, 9482-9489.

(9) Dutta, N. N.; Raghavan, K. V. Mass transfer and hydrodynamic characteristics of loop reactors with downflow liquid jet ejector. Chem. Eng. J. 1987, 36, 111-121.

(10) van Dierendonck, L. L.; Zahradník, J.; Linek, V. Loop Venturi ReactorA Feasible Alternative to Stirred Tank Reactors? Ind. Eng. Chem. Res. 1998, 37, 734-738.

(11) Lehtonen, J.; Kaplin, J.; Salmi, T.; Haario, H.; Vuori, A.; Tirronen, E. Modelling and scale-up of a loop reactor for hydrogenation processes. Chem. Eng. Sci. 1999, 54, 2793-2798.

(12) Warmeling, H.; Behr, A.; Vorholt, A. J. Jet loop reactors as a versatile reactor set up - Intensifying catalytic reactions: A review. Chem. Eng. Sci. 2016, 149, 229-248.

(13) Roininen, J.; Alopaeus, V.; Toppinen, S.; Aittamaa, J. Modeling and Simulation of an Industrial Trickle-Bed Reactor for Benzene Hydrogenation: Model Validation against Plant Data. Ind. Eng. Chem. Res. 2009, 48, 1866-1872.

(14) Bhaskar, M.; Valavarasu, G.; Sairam, B.; Balaraman, K.; Balu, K. Three-phase reactor model to simulate the performance of pilot-plant and industrial trickle-bed reactors sustaining hydrotreating reactions. Ind. Eng. Chem. Res. 2004, 43, 6654-6669.

(15) Khadilkar, M. R.; Mills, P. L.; Dudukovic, M. P. Trickle-bed reactor models for systems with a volatile liquid phase. Chem. Eng. Sci. 1999, 54, 2421-2431.

(16) Poissonnier, J.; Thybaut, J. W.; Marin, G. B. Understanding and optimization of chemical reactor performance for bimodal reaction sequences. AIChE J. 2017, 63, 111-119.
(17) Poissonnier, J.; Pelckmans, M.; Van Waes, F.; Moonen, K.; Sels, B. F.; Thybaut, J. W.; Marin, G. B. Kinetics of Homogeneous and Heterogeneous Reactions in the Reductive Aminolysis of Glucose with Dimethylamine. Appl. Catal., B 2017, submitted for publication.

(18) Brown, P. N.; Hindmarsh, A. C.; Petzold, L. R. Using Krylov Methods in the Solution of Large-Scale Differential-Algebraic Systems. SIAM J. Sci. Comput. 1994, 15, 1467-1488.

(19) Zacca, J. J.; Ray, W. H. Modelling of the liquid phase polymerization of olefins in loop reactors. Chem. Eng. Sci. 1993, 48, 3743-3765.

(20) Wild, G.; Larachi, F.; Charpentier, J. Heat and mass transfer in gas-liquid-solid fixed bed reactors. In Heat and mass transfer in porous media; Elsevier: Amsterdam, The Netherlands, 1992.

(21) Sato, Y.; Hirose, T.; Takahashi, F.; Toda, M. Performance of fixed-bed catalytic reactor with co-current gas-liquid flow. PACHEC 1972, 72, 187-196.

(22) Welty, J. Fundamentals of Momentum, Heat and Mass Transfer, 5th ed.; Wiley Global Education: Hoboken, NJ, 2007.

(23) Fukushima, S.; Kusaka, K. Liquid-phase volumetric and masstransfer coefficient, and boundary of hydronamic flow region in packed column with cocurrent downward flow. J. Chem. Eng. Jpn. 1977, 10, $468-474$. 